\title{
In the hour of Sugammadex
}

\author{
Jin Young Chon \\ Department of Anesthesiology and Pain Medicine, The Catholic University of Korea School of Medicine, Seoul, Korea
}

Sugammadex is a modified gamma-cyclodextrin which is showing favorable outcomes regarding reversal of neuromuscular blockade, especially by rocuronium. It is designed to encapsulate rocuronium and being considered a new class of drugs as selective relaxant binding agents. It has given countless benefits to the patients at risk of incomplete or delayed recovery after neuromuscular block and has renown for another milestone in anesthesia practice. Recurrence of neuromuscular block has not been reported to be associated with the provided doses of sugammadex that are adequate for selected for reversal. Acceptable profiles are brought to light telling safety of sugammadex. However, some questions related to the twitch characteristics those resembled succinylcholine when reversal, the application for rocuronium anaphylaxis, and the hypersensitivity or anaphylaxis to sugammadex remain and are need of further investigation. It is imperative that potential problems that we need attention may include the patient's history of pulmonary disease and allergic disease for using sugammadex. (Korean J Anesthesiol 2013; 64: 3-5)

Key Words: Allergy, Hypersensitivity, Neuromuscular blockade, Patient safety, Sugammadex.

The time to practically use Sugammadex throughout Korea has come.

It might be right time when we contemplate the clinical use of sugammadex carefully.

Sugammadex is a modified gamma-cyclodextrin which is showing favorable outcomes regarding the reversal of neuromuscular blockade, especially by rocuronium. It is designed to encapsulate rocuronium and providing a rapid reversal from the neuromuscular block. It becomes a new class of drugs as selective relaxant binding agents [1] and is currently available for over 50 countries [2].

The dose for the reversal of moderate block (at two TOF responses) is known to be $2 \mathrm{mg} / \mathrm{kg}$, 4 to $8 \mathrm{mg} / \mathrm{kg}$ for a profound block (a level of two post-tetanic responses) and a dose of 16 $\mathrm{mg} / \mathrm{kg}$ for immediate rescue reversal [3-5]. Sugammadex has provided countless benefits to patients at risk of incomplete or delayed recovery after neuromuscular block accordingly. This new drug received reviewed as a milestone in anesthesia with high praise according to the unrivaled mechanism of drug action [4]. Current available data strongly bring to mind that

Received: October 10, 2012. Accepted: October 11, 2012.

Corresponding author: Jin Young Chon, M.D., Ph.D., Department of Anesthesiology and Pain Medicine, The Catholic University of Korea School of Medicine, 362, Yeouido-dong, Yeongdeungpo-gu, Seoul 150-713, Korea. Tel: 82-2-3779-1164, Fax: 82-2-783-0368, E-mail: anestha@ catholic.ac.kr

(c) This is an open-access article distributed under the terms of the Creative Commons Attribution Non-Commercial License (http:// creativecommons.org/licenses/by-nc/3.0/), which permits unrestricted non-commercial use, distribution, and reproduction in any medium, provided the original work is properly cited. 
sugammadex for regular use might have the potential to shorten recovery times. Although titrated administered neuromuscular blockades could be perceived in clinical routine, increased recovery times after reversal with acetylcholine inhibitors are not usually discerned when neuromuscular monitoring is waived. Therefore, the exclusive ability of sugammadex to antagonize any degree of residual neuromuscular block effectively and affirmatively could prevent untimely extubation related to the acetylcholine inhibitor based reversal.

The accepted current concept of a TOF ratio of 0.9 is favorable for satisfactory recovery as safe with regard to the risk of recurarization problems [3]. Post-operative respiratory and airway problems were not satisfactory until the adductor pollicis TOF ratio reached 0.9 [6]. $98 \%$ of the patients were recovered within 5 minutes after $2 \mathrm{mg} / \mathrm{kg}$ sugammadex and the recovery from the neuromuscular block of rocuronium to a TOF ratio of 0.9 is around 13 times faster with sugammadex compared to the conventional neostigmine [7].

However, some questions related to the twitch characteristics remain and require further investigation.

The use of sugammadex for deep blockades had shown to report an interesting phenomenon. The TOF recovery before complete recovery of single twitch had a difference of up to 5 minutes between the types of stimulation [8]. This study demonstrated that after reversal of rocuronium-induced neuromuscular block by sugammadex, the return of a normal TOF ratio can precede the return of a normal twitch height, dose-dependently. According to those results, the traditional relationship between TOF ratio and $\mathrm{T} 1$ recovery may not be valid anymore. The recovery of the TOF ratio to 0.9 precedes the recovery of $\mathrm{T} 1$, and the TOF ratio might be fully recovered not for T1. Therefore, the TOF ratio may no longer be the only measurement concept regarding adequate reversal after reversal with sugammadex. The twitch height has to be considered with the TOF ratio in this case. Moreover, it is interesting that this response has a point of similarity as the pattern of a partial succinylcholine block as depression of $\mathrm{T} 1$ with the continuation of TOF.

This phenomenon will be further investigated in the near future from not only the complete reversal considered with the presence of $\mathrm{T} 1$ depression, but also in regards to the unique characteristics of sugammadex reversal.

Secondly, the effect of sugammadex on which the eyes rested is anaphylaxis.

Allergic reactions to neuromuscular blockades are the most common cause of anaphylaxis in general anesthesia. Rocuronium and succinylcholine were the most common agents related with anaphylaxis [9]. Cisatracurium as the representative drug of benzylisoqunolinium also cannot be free from the allergic reaction. Kounis syndrome [10], anaphylaxis after negative skin test [11] and anaphylactoid reactions [12] were reported.

Jones and Turkstra [13] first described that sugammadex might be used to eliminate rocuronium from the circulation of the one who had rocuronium induced anaphylaxis and then stop or delay the immunologic progression cascades. There are several uncertainties regarding this strategy. Responsible parts of the rocuronium molecule for anaphylaxis are not known. Involvement of the IgE antibody to rocuronium, the differences of plasma half-life between the sugammadex-rocuronium complex and the rocuronium molecule itself, the attachments by the exposed part of the rocuronium molecule after the complex formation according to the allergenic determinant and the interrelationships of binding among rocuronium, sugammadex and IgE antibodies need to be revealed, Since anaphylaxis is widely known for its continuence after removal of the target allergen.

Lastly, there are reported issues relevant to the allergic reaction of sugammadex with regards to the clinical dosages [14-17]. Five cases were reported from Japan [14,15,17]. Of the cases, four involved females, and one case involving a male was reported from Spain [16]. At the high dose range (32-96 mg/ $\mathrm{kg}$ ), one healthy Dutchman reported suffering from possible hypersensitivity to sugammadex [18].

In the in vitro rat model, sugammadex itself did not directly affect the contractile function in bronchial smooth muscles [19]. However, among the patients with pulmonary disease, it was reported that 2 out of 77 American patients (2.6\%) represented bronchospasm after sugammadex [20]. Those two patients had a history of asthma and belonged to the $4 \mathrm{mg} / \mathrm{kg}$ group. The mechanism was unclear and not explained in the article but bronchial smooth muscle hyperresponsiveness might be involved.

So if the time comes when we demand a change, we will all know how to make it happen. Problems often arise from small simple mistakes much like the way a wall crumbles from plants growing in the interstices between bricks.

Anesthesiologists need to be more vigilant in using sugammadex for clinical practice.

The patient's history of pulmonary disease and allergic disease are key considerations when contemplating the use of sugammadex.

\section{References}

1. Naguib M, Brull SJ. Update on neuromuscular pharmacology. Curr Opin Anaesthesiol 2009; 22: 483-90.

2. Fuchs-Buder T, Meistelman C, Schreiber JU. Is sugammadex economically viable for routine use. Curr Opin Anaesthesiol 2012; 25: 21720 . 
3. Shields M, Giovannelli M, Mirakhur RK, Moppett I, Adams J, Hermens Y. Org 25969 (sugammadex), a selective relaxant binding agent for antagonism of prolonged rocuronium-induced neuromuscular block. Br J Anaesth 2006; 96: 36-43.

4. Naguib M. Sugammadex: another milestone in clinical neuromuscular pharmacology. Anesth Analg 2007; 104: 575-81.

5. Caldwell JE, Miller RD. Clinical implications of sugammadex. Anaesthesia 2009; 64 Suppl 1: 66-72.

6. Sundman E, Witt H, Olsson R, Ekberg O, Kuylenstierna R, Eriksson LI. The incidence and mechanisms of pharyngeal and upper esophageal dysfunction in partially paralyzed humans: pharyngeal videoradiography and simultaneous manometry after atracurium. Anesthesiology 2000; 92: 977-84.

7. Blobner M, Eriksson LI, Scholz J, Motsch J, Della Rocca G, Prins ME. Reversal of rocuronium-induced neuromuscular blockade with sugammadex compared with neostigmine during sevoflurane anaesthesia: results of a randomised, controlled trial. Eur J Anaesthesiol 2010; 27: 874-81.

8. Staals LM, Driessen JJ, Van Egmond J, De Boer HD, Klimek M, Flockton EA, et al. Train-of-four ratio recovery often precedes twitch recovery when neuromuscular block is reversed by sugammadex. Acta Anaesthesiol Scand 2011; 55: 700-7.

9. Brereton A, Russell WJ. Anaphylaxis to muscle relaxants: an audit of ten years of allergy testing at the Royal Adelaide Hospital. Anaesth Intensive Care 2012; 40: 861-6.

10. Yang YL, Huang HW, Yip HK, Jawan B, Tseng CC, Lu HF. Acute coronary syndrome in cisatracurium-induced anaphylactic shock: Kounis syndrome. Acta Anaesthesiol Taiwan 2008; 46: 184-6.

11. Fraser BA, Smart JA. Anaphylaxis to cisatracurium following negative skin testing. Anaesth Intensive Care 2005; 33: 816-9.

12. Krombach J, Hunzelmann N, Koster F, Bischoff A, HoffmannMenzel H, Buzello W. Anaphylactoid reactions after cisatracurium administration in six patients. Anesth Analg 2001; 93: 1257-9.

13. Jones PM, Turkstra TP. Mitigation of rocuronium-induced anaphylaxis by sugammadex: the great unknown. Anaesthesia 2010; 65: 8990.

14. Godai K, Hasegawa-Moriyama M, Kuniyoshi T, Kakoi T, Ikoma K, Isowaki $\mathrm{S}$, et al. Three cases of suspected sugammadex-induced hypersensitivity reactions. Br J Anaesth 2012; 109: 216-8.

15. Hasegawa K, Kinoshita M, Asahi T. Difficult ventilation after sugammadex administration: a case report. Masui 2012; 61: 749-51.

16. Menendez-Ozcoidi L, Ortiz-Gomez JR, Olaguibel-Ribero JM, Salvador-Bravo MJ. Allergy to low dose sugammadex. Anaesthesia 2011; 66: 217-9.

17. Motoyama Y, Izuta S, Maekawa N, Chuma R. Case of anaphylactic reaction caused by sugammadex. Masui 2012; 61: 746-8.

18. Peeters PA, van den Heuvel MW, van Heumen E, Passier PC, Smeets JM, van Iersel T, et al. Safety, tolerability and pharmacokinetics of sugammadex using single high doses (up to $96 \mathrm{mg} / \mathrm{kg}$ ) in healthy adult subjects: a randomized, double-blind, crossover, placebocontrolled, single-centre study. Clin Drug Investig 2010; 30: 867-74.

19. Yoshioka N, Hanazaki M, Fujita Y, Nakatsuka H, Katayama H, Chiba Y. Effect of sugammadex on bronchial smooth muscle function in rats. J Smooth Muscle Res 2012; 48: 59-64.

20. Amao R, Zornow MH, Cowan RM, Cheng DC, Morte JB, Allard MW. Use of sugammadex in patients with a history of pulmonary disease. J Clin Anesth 2012; 24: 289-97. 